\author{
dspace.vutbr.cz
}

\title{
Spray characteristics and liquid distribution of multi- hole effervescent atomisers for industrial burners
}

\author{
JEDELSKÝ, J.; JÍCHA, M.
}

Applied Thermal Engineering

2016, vol. 96, March 2016, pp. 286-296

ISSN: 1359-4311

DOI: https://doi.org/10.1016/j.applthermaleng.2015.11.079

Accepted manuscript

(C) 2018. This manuscript version is made available under the CC-BY-NC-ND 4.0 license (http://creativecommons.org/licenses/by-nc-nd/4.0/), doi:

https://doi.org/10.1016/j.applthermaleng.2015.11.079

Final version available from https://www.sciencedirect.com/science/article/pii/s1359431115013253 


\author{
Jan Jedelský ${ }^{1}$ and Miroslav Jícha
}

Brno University of Technology, Faculty of Mechanical Engineering, Technicka 2896/2, 61669 Brno, Czech Republic

Abstract

The present paper provides an experimental study and optimization of multi-hole effervescent atomizers for industrial burners using oil-based fossil, bio- or waste fuels with prospects of emission reduction. Several multihole nozzles were designed based on our previous work. We probed the spray quality by Phase-Doppler anemometry. 3-D plots of Sauter mean diameter and mean droplet velocity demonstrate their spatial distribution within the spray. The effect of geometrical and operational factors on the spray is discussed. Droplet sizevelocity correlations as well as the size and velocity distributions are presented, and differences are found against other investigations. A spray macrostructure is photographically observed and spray cone angles of the multihole nozzles are analysed. An internal two-phase flow is estimated using the Baker's map for horizontal twophase flow. Our previous two-phase flow visualizations suggested a liquid-gas gravitational separation when the multi-hole atomizer operated horizontally. This issue is addressed here; the results of spray heterogeneity measurements document that fuel flow rates through individual exit holes differ significantly. This difference spans between 0 and $70 \%$ depending on the nozzle design and flow regime. Effervescent sprays are unsteady under some operating conditions; spray unsteadiness was detected at low pressure and low gas-to-liquid-ratios.

\footnotetext{
${ }^{1}$ Corresponding author. Tel.: +420 541143 266, Fax: +420 541143 365, E-mail: jedelsky@fme.vutbr.cz Abbreviations: Gas-to-Liquid-Ratio (GLR), Light Heating Oil (LHO), Spray Cone Angle (SCA), Spray Cone Half-Angle (SCHA), Phase-Doppler Anemometer (PDA), Root-Mean-Square (RMS)
} 
Keywords: Droplet size; Effervescent atomization; Liquid-gas separation; Multi-hole atomizers; Spray unsteadiness; Two-phase flow.

\section{Introduction}

Effervescent atomizers are more and more frequent in various engineering applications where the liquid is to be fragmented into droplets; they show a potential for combustion applications. Combustion efficiency and exhaust gas emissions strongly relate to the spray quality and liquid distribution in the combustion chamber. Effervescent atomizers allow for low exhaust gas emissions due to the atomizing air present in the spray core. Their major advantages stem from low sensitivity to the rheological properties of sprayed liquid and the wide range of liquid flow rates where these atomizers provide a good atomization. Effervescent atomizers could work well even with less-refined or viscous fuels such as today preferred liquid wastes, by-products in chemical processes or fuels from renewable resources [1] (e.g. raw vegetable oils [2] and cottonseed oil methyl esters [3]). Furthermore, the effervescent atomizers have a larger orifice than conventional atomizers, which alleviates clogging problems and facilitates atomizer fabrication [4].

Fuel pumps of today's engines with pressure injectors consume a considerable portion of the engine power, so designers are looking for advanced atomization technologies with low energy consumption and reduced droplet size [5]. Effervescent nozzles produce a fine spray at low injection pressure so this twin-fluid technology suits for new combustion applications, such as advanced gas turbines concepts [6]. The liquid distribution and SCA (Spray Cone Angle) in the fuel sprays, studied in [7] and [8-11] respectively, belong to the important atomizer parameters that must be harmonised with the combustor requirements.

Chen and Lefebvre [8] examined the SCAs produced by a plain-orifice effervescent atomizer. Their results show a parabolic behaviour of the SCA with the GLR (Gas-to-Liquid-Ratio) change; increase in SCA for low GLR up to a maximum at GLR about 6-9\%, depending on the pressure, and then a decrease in SCA with continuing GLR increase. They showed substantially wider SCAs of the effervescent sprays than those produced by plain-orifice pressure atomizers. Whitlow and Lefebvre [7] in the effervescent spray of water-air mixture found effective SCAs $\sim 23^{\circ}$ for operation in the bubbly flow regime with GLR $=1.2 \%$ and $16^{\circ}$ in annular flow regime with GLR $=12 \%$. Wade et al. [9] studied the SCA in the range of GLR from 0.015 to 0.32 and injection pressure from 12 to $33 \mathrm{MPa}$. They found the SCA increasing with an increase in GLR and injection pressure. Sovani et al. [11] investigated an effervescent spray in high ambient density environments for different injection 
and $11.5^{\circ}$ over the entire range of independent parameters studied, and its linear increase with increasing injection pressure or GLR at all ambient pressures. We [13] studied liquid concentration based half-angles of the effervescent spray; the SCHA varies with operating conditions between $7.9^{\circ}$ and $12.2^{\circ}$. GLR causes the SCHA narrowing while the inlet pressure has an indistinctive effect. Sovani et al. [10] investigated the influence of exit orifice diameter, aerator pore size, atomizing GLR, and injection pressure on the SCHA. Their data show that the SCHA ranges from 7 to $11^{\circ}$, regardless of all the parameters mentioned. Gong and Fu [12] measured several configurations of a swirling gas-liquid atomizer. They found the SCHA (between $22^{\circ}$ and $45^{\circ}$ ) strongly dependent on the nozzle geometry.

These reported works document that the SCA in a plain-orifice effervescent sprays vary with inlet pressure and with GLR. The SCA typically ranges between 14 and $24^{\circ}$; it is significantly lower than the SCA in e. g. pressure-swirl sprays and namely the value required in most of the conventional burners [12]. It leads us to focus on a multi-hole arrangement of the final discharge orifices.

Multi-hole effervescent atomizers are rarely studied, and their spray characteristics are not sufficiently resolved. Whitlow et al. $[7,14]$ tested an effervescent atomizer with multi-hole and annular orifices. They concluded that the performance characteristics of multi-hole atomizers were essentially the same as those of single-hole atomizers for the same length/diameter ratio of the final orifice. Li et al. [15] found no effect of the discharge orifices number on the mean drop size. Multi-hole effervescent atomizers were investigated by Dutta et al. [16] with no comparison of their atomizer with a similar single-orifice atomizer. Moore [17] characterized multi-hole nozzles with four different geometries and found differences in their performance. Barreras et al. [18] characterized multi-hole industrial twin-fluid atomizers with the aim to replace the Y-jet nozzles. Sovani et al. [19] stated that with non-homogeneous two-phase flow inside a multi-hole atomizer the sprays produced by individual holes exhibit different characteristics.

Based on the previous works we aimed to test and optimize a multi-hole effervescent atomizer, applicable to industrial burners, which generates a stable spray in large turn-down ratio, with small Sauter mean diameter, $D_{32}$, at low fuel pressures and with low GLR. This atomizer is intended to spray an LHO (Light Heating Oil) or waste 81 liquid fuels using air as an atomizing gas. It will be applied to a range of high power industrial burners (up to $40 \mathrm{MW}$ ) replacing a multi-hole Y-jet atomizer originally used. This experimental research is a follow-up to the study conducted previously on single-hole effervescent atomizers with wide geometrical variations of the atomizer [20]. Based on this study, a multi-hole atomizer was designed in several geometrical modifications. In this paper, the main spray characteristics of these modifications are compared and analysed for a range of inlet 
pressures (0.2-1.0 MPa) and atomizing GLRs (3-10\%). The internal two-phase flow is estimated with the Baker's two-phase flow map using the measured flow characteristics. Two major combustion-related issues are addressed: spray heterogeneity and spray unsteadiness.

\section{Experimental setup}

The experimental data included in this work were acquired by cold testing of a set of multi-hole effervescent atomizers in the Spray laboratory at Brno University of Technology. The atomizers were operated on a cold test bench with fluid supply system that is documented in [20]. Following paragraphs describe the atomizer design and the equipment used for spray measurement.

\subsection{Atomizer description and operation}

Spraying of waste liquids and slurries requires large flow cross-sections to prevent clogging due to possibly contained solid particles. We, therefore, amongst several versions of the effervescent atomizers, chose the “outside-in” gas injection configuration (referred as the type A in [20]). Based on our previous findings acquired on a set of single-hole atomizers [20] and tests of several multi-hole atomizers (E1-E7, unpublished results), we designed seven new multi-hole atomizers, E8-E14. The atomizers E8 and E9 use a concept shown in Fig. 1, top. The liquid (LHO) enters the aerator from the left-hand side. The atomising air enters the aerating tube through a set of holes and interacts with the liquid. Physical properties of LHO at room temperature are as follows: $\sigma_{l}=0.0297 \mathrm{~kg} / \mathrm{s}^{2}, \rho_{l}=874 \mathrm{~kg} / \mathrm{m}^{3}, \mu_{l}=0.0185 \mathrm{~kg} /(\mathrm{m} \cdot \mathrm{s})$. The internal diameter of the mixing chamber, $d_{c}$, is $16 \mathrm{~mm}$. A conical shaft (insert) is placed inside the chamber; thus formed annular slot for the flowing mixture gradually enlarges from $1 \mathrm{~mm}$ at the position of the first row of aerator holes to the full cross-section. There are 168 holes of $1.2 \mathrm{~mm}$ in diameter arranged in 21 lines; eight holes in each line are turned by $45^{\circ}$ against the holes in the neighbour line. The last hole line ends up in the axial position of the shaft tip. The nozzle exit part contains six orifices; each with a diameter of $d_{o}=2.2 \mathrm{~mm}$. The axes of the individual orifices form a full angle, $\alpha$, of $60^{\circ}$ for the atomizer E8 and $90^{\circ}$ for the atomizer E9.

111 The atomizer E10 has $d_{c}=10 \mathrm{~mm}$ and no insert inside the chamber. This atomizer features only the first line of six aerator holes, inclined at an angle of $60^{\circ}$ relative to the main atomizer axis in the flow direction, and the

113 last line of four aerator holes that are arranged tangentially (shown in the section A-A). The six orifices in the nozzle tip with $d_{o}=2.2 \mathrm{~mm}$ are arranged to form a full angle of $\alpha=60^{\circ}$. 

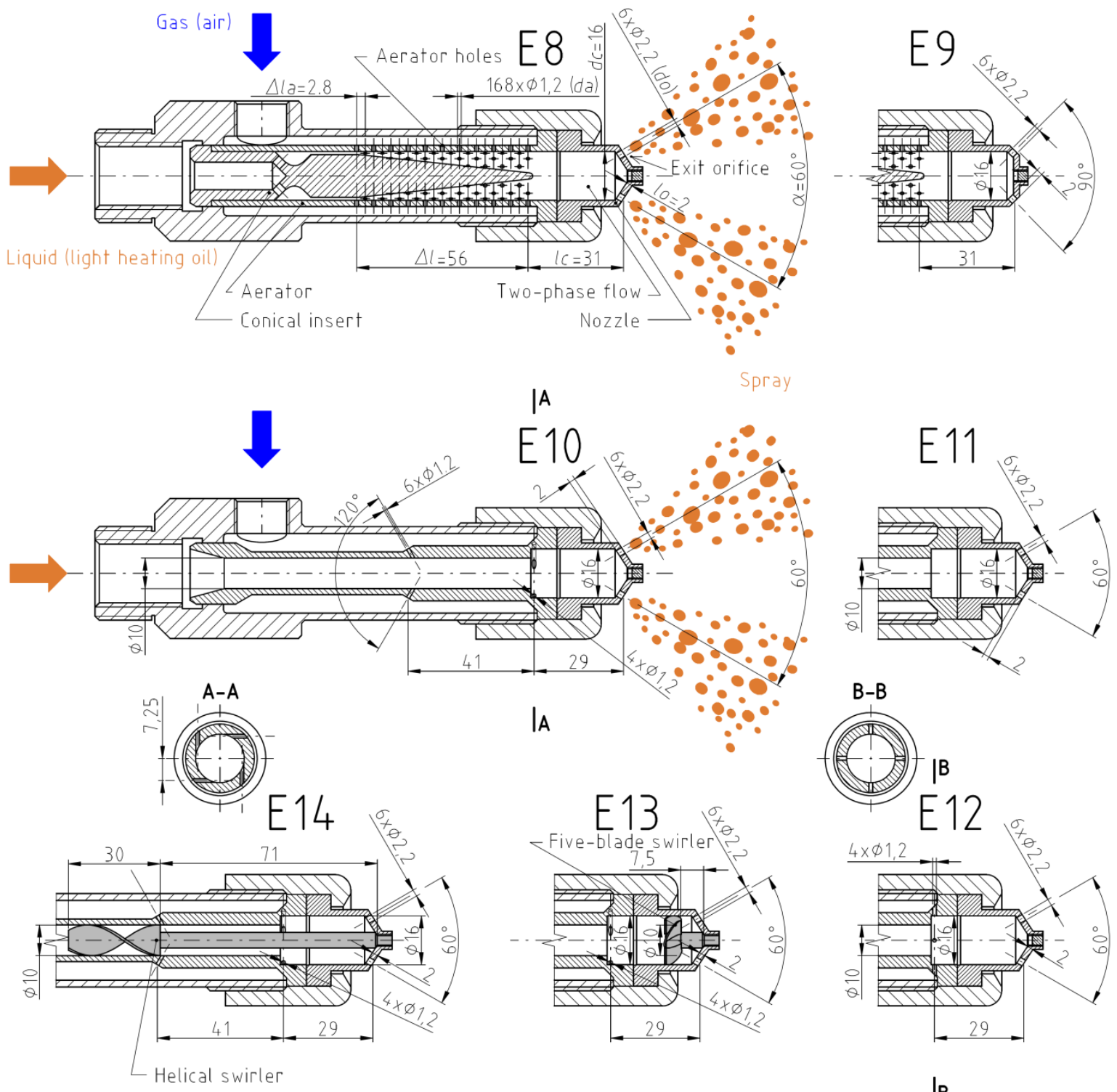

IB

Fig. 1: Schematic layouts of the designed atomizers.

Four more atomizers were derived from the atomizer E10. A modification E11 does not feature the last line

118 of four aerator holes while in E12 the last four aerator holes are radially arranged (the same way as in E8 and E9,

119 see the section B-B). Atomizers E13 and E14 contain a swirling part inside the aerator. The swirler in E13 has a

120 form of the five-blade propeller with the axial length of $5 \mathrm{~mm}$. Its distance of $7.5 \mathrm{~mm}$ from the nozzle head is

121 fixed using a mandrel of $4 \mathrm{~mm}$ in diameter, which is screwed into the nozzle tip. The blade inclination is $55^{\circ}$

122 relative to the atomizer axis, and their outer diameter is flush with the inner aerator wall. The version E14 
123 features a $30 \mathrm{~mm}$ long helical swirler with outer diameter mating with the inner aerator diameter. This swirler,

124 with a helix of $46 \mathrm{~mm} / \mathrm{rev}$, is located just ahead the first row of aeration holes.

125

126

Table 1 Operating conditions and RMS value of the fluctuating pressure inside the mixing chamber.

\begin{tabular}{|c|c|c|c|c|c|c|c|c|c|}
\hline \multicolumn{2}{|c|}{ atomizer } & \multicolumn{2}{|c|}{ E8, E9 } & \multirow{2}{*}{$\begin{array}{c}\text { E8 } \\
p_{R M S}\end{array}$} & \multirow{2}{*}{$\begin{array}{c}\text { E9 } \\
p_{R M S}\end{array}$} & \multicolumn{2}{|c|}{ E10, E12 } & \multirow{2}{*}{$\begin{array}{l}\mathrm{E} 10 \\
p_{R M S}\end{array}$} & \multirow{2}{*}{$\begin{array}{c}\mathrm{E} 12 \\
p_{R M S}\end{array}$} \\
\hline$p_{g}$ & $G L R$ & $\Delta_{p}$ & $Q_{l}$ & & & $\Delta_{p}$ & $Q_{1}$ & & \\
\hline (MPa) & (\%) & $(\mathrm{kPa})$ & $\left(\mathrm{ml} \cdot \mathrm{s}^{-1}\right)$ & $(\mathrm{kPa})$ & $(\mathrm{kPa})$ & $(\mathrm{kPa})$ & $\left(\mathrm{ml} \cdot \mathrm{s}^{-1}\right)$ & $(\mathrm{kPa})$ & $(\mathrm{kPa})$ \\
\hline 0.2 & 3 & -25 & 144 & 2.35 & 3.10 & 17 & 118 & 2.49 & 1.13 \\
\hline 0.2 & 5 & -13 & 110 & 2.23 & 1.65 & 41 & 84 & 1.57 & 1.61 \\
\hline 0.2 & 10 & -4 & 71 & 2.21 & 3.03 & 74 & 49 & 1.50 & 2.21 \\
\hline 0.6 & 3 & -78 & 299 & 1.40 & 1.83 & -7 & 274 & 0.76 & 0.86 \\
\hline 0.6 & 5 & -48 & 236 & 1.31 & 0.87 & 36 & 204 & 0.87 & 0.89 \\
\hline 0.6 & 10 & -16 & 156 & 0.83 & 0.53 & 113 & 128 & 0.98 & 1.11 \\
\hline 1.0 & 3 & -151 & 438 & 0.57 & 0.58 & -33 & 395 & 0.73 & 0.88 \\
\hline 1.0 & 5 & -91 & 340 & 0.71 & 0.97 & 32 & 301 & 0.95 & 0.56 \\
\hline 1.0 & 10 & -45 & 232 & 0.68 & 0.52 & 157 & 189 & 0.57 & 0.90 \\
\hline
\end{tabular}

Atomizers inside burners have to ensure a fine spray in the operation range from minimum to maximum fuel

130 flow rates, $Q_{l}$. A design turn-down ratio for our atomizers was set to 1:5. Some other parameters were to be fixed

131 at the beginning to allow the atomizer sizing. We were limited by the maximum available supply pressures of air

132 and liquid of $1 \mathrm{MPa}$. Based on our previous tests [20], we chose the minimum fluid supply pressure of $0.2 \mathrm{MPa}$

133 and set the GLR range between 3\% and 10\%. These pressure and GLR limits should guarantee the expected

134 turn-down ratio as well as a stable and fine spray under low atomizing air consumption. The GLR range of 3-

$13510 \%$ was found useful for atomizers inside burners [20], and similar or higher GLRs of effervescent atomizers

136 are frequently used for combustion and other applications [7, 14, 15, 21, 22].

137 The maximum liquid flow rate is obtained at $p_{g}=1.0 \mathrm{MPa}$ and GLR $=3 \%$ and the minimum flow rate at $138 p_{g}=0.2 \mathrm{MPa}, \mathrm{GLR}=10 \%$. Knowing the liquid and gas physical properties and the required maximum liquid

139 flow rate $(0.35 \mathrm{~kg} / \mathrm{s})$ at corresponding $p_{g}$ and GLR, we were able to estimate the cross-section of exit orifice

140 holes according to the procedure given in [20], Appendix 2. We chose six exit orifices, as a compromise, to

141 allow a uniform fuel distribution inside the burner with a minimum interference between jets. Then we found the 
142

143

144

145

146

147

148

149

150

151

152

153

154

155

156

157

158

159

160

161

162

163

164

165

166

167

168

169

170

171

exit orifice diameter $d_{o}=2.2 \mathrm{~mm}$. The other main atomizer parameters to set were as follows: diameter $\left(d_{a}\right)$, number $\left(n_{a}\right)$, direction and placement of air injection holes, length $\left(l_{c}\right)$ and diameter $\left(d_{c}\right)$ of the mixing chamber. The parametric study of single-hole effervescent atomizers [20] found the optimum ratio (where the lowest $D_{32}$ was achieved) between the mixing chamber and the exit orifice diameter $r_{d c}=d_{c} / d_{o}=4$ and a reasonable increase in $D_{32}$ for smaller ratios. The corresponding optimum of the ratio between the areas of the mixing chamber and exit orifices was $r_{A c}=A_{c} / A_{o}=16$. The area ratio controls the internal flow character while the diameter ratio affects the primary breakup conditions. We, for the multi-hole atomizers, chose a smaller $r_{A c}$ of $8.8\left(r_{d c}=7.3\right.$ for atomizers E8, E9 with $\left.d_{c}=16 \mathrm{~mm}\right)$ and $3.4\left(r_{d c}=4.5\right.$ for E10-E14 with $\left.d_{c}=10 \mathrm{~mm}\right)$ to roughly keep the diameter ratio and namely to suppress an expected vertical liquid-gas gravitational separation in the case of the horizontal operation of the atomizers (discussed below in Section 3.4).

We set the relative aeration area $r_{a}=n_{a} \cdot A_{a} / A_{o}$ of atomizers E8 and E9 according to [20] to $r_{a}=8.3$. We reduced it for the other atomizers to 0.5 (E10, E12-E14) and even to 0.3 (E11) to promote the gas-liquid mixing due to increased air injection velocity. The diameter of air injection holes was set to $d_{a}=1.2 \mathrm{~mm}$ for easy fabrication. Their direction can enhance the mixing process if the air is injected at high velocity (it applies for E10-E14 namely at high GLR). We, therefore, tangentially oriented the second air-hole set in the atomizers E10, E13 and E14 in contrast with E12, where these were drilled radially. We used a small value of the relative chamber length, $r_{l c}=l_{c} / d_{c}=1.9$ (E8, E9) and 1.8 (E10-E14) to suppress the gravitational separation. Another way of the internal flow modification is an application of inserts; atomizers E8 and E9 use a conical insert that provides a uniform pressure drop along the air-injection length and allows the air to gradually penetrate into the liquid. On the other hand, the atomizers E13 and E14 use screw-like inserts to swirl the liquid (E13) and to swirl the mixture (E14).

The global SCA produced by multi-hole atomizers depends on the expansion of the mixture discharged from an individual exit hole and namely on the exit nozzle angle $\alpha$. We use two atomizers with the same internal geometry, which differ only in the exit nozzle angle, $\alpha$, to study the effect of $\alpha$ on SCA: E8 with $\alpha=60^{\circ}$ and E9 with $90^{\circ}$. All the atomizers are provided with a socket at the nozzle tip for internal pressure sensing and an eventual insert fixation.

We performed detailed tests for all combinations of $p_{g}(0.2,0.6$ and $1.0 \mathrm{MPa}$ ) and GLR (of 3, 5 and $10 \%$ ). The operating conditions together with the difference between the inlet air and fuel pressures $\left(\Delta_{p}=p_{g}-p_{l}\right)$ of atomizers E8, E9, E10, and E12 are documented in Table 1. The flow rates and pressure differences are referred to jointly for E8/E9 and E10/E12 as the atomizer E9 operated with the same flow rates as E8, and the atomizers 

unable to cover the designed GLR range, so we excluded it from further testing. The quantity $p_{R M S}$ refers to the spray unsteadiness, and it is described later on in Section 3.5.

175

\subsection{Phase-Doppler Anemometer}

Size and velocity of droplets in the spray were measured using a commercial PDA (Phase-Doppler Anemometer) by Dantec Dynamics A/S (Skovlunde, Denmark). This 1D system was equipped with an Ar-Ion ${ }^{+}$ laser with maximum total beam power of $300 \mathrm{~mW}$ and beam waste diameter of $0.82 \mathrm{~mm}$. The spectral line $514.5 \mathrm{~nm}$ of the CW-laser beam with power up to $90 \mathrm{~mW}$ and horizontal polarization was split into two parallel beams $60 \mathrm{~mm}$ distant, using a transmitting optics 58N10. The focal length of both the transmitting and receiving lenses was $500 \mathrm{~mm}$, which resulted in a half-intersection angle of $3.43^{\circ}$ between the transmitted beams. The

183 beam crossing formed a small measurement volume where the droplets were detected. The frequency of one of the beams was shifted by $40 \mathrm{MHz}$. This configuration led to a fringe separation of $4.3 \mu \mathrm{m}$. First-order refracted light was collected using a Dantec 57X10 receiving optics equipped with three photo-detectors at an elevation angle of $\pm 0.68^{\circ}$. The receiving probe was positioned at the scattering angle of $69^{\circ}$. A micrometer screw in the receiver optics was typically set to $0 \mathrm{~mm}$, which enabled us to measure the droplet size up to $350 \mu \mathrm{m}$. A Dantec 58N50 signal processor was set to measure the velocity within a range of -25.8 to $128.9 \mathrm{~m} \cdot \mathrm{s}^{-1}$ at $36 \mathrm{MHz}$ bandwidth. The measured diameters $D_{i}$ and axial velocities $v_{i}$ of individual droplets were used for estimation of

190 Sauter mean diameter $D_{32}=\sum_{i=1}^{n} D_{i}^{3} / \sum_{i=1}^{n} D_{i}^{2}$ and mean axial velocity $v_{m}=\sum_{i=1}^{n} v_{i} / n$ in discrete spray 191 positions.

\section{Results and discussion}

A spray quality of single-hole effervescent atomizers and early results for the multi-hole atomizers in comparison with Y-jet atomizers were presented in previous works [20, 23]. Here we describe the results for

196 multi-hole atomizers E8-E14. The greatest attention is paid to the atomizer E10, which was chosen as a representative of this set.

198 
Figs. 2 and 3 photographically document the spray macrostructure of atomizers E8 and E9 that share the same internal geometry and differ only in the exit nozzle angle, $\alpha$, which is $60^{\circ}$ for E8 and $90^{\circ}$ for E9. The $\alpha$ angle determines the flow direction of the discharged mixture and thus controls the global SCA created by all the streams. The global SCA is an essential parameter for multi-hole atomizers. We estimated the SCA using the spray images at an axial distance of $200 \mathrm{~mm}$ from the atomizer exit.

205
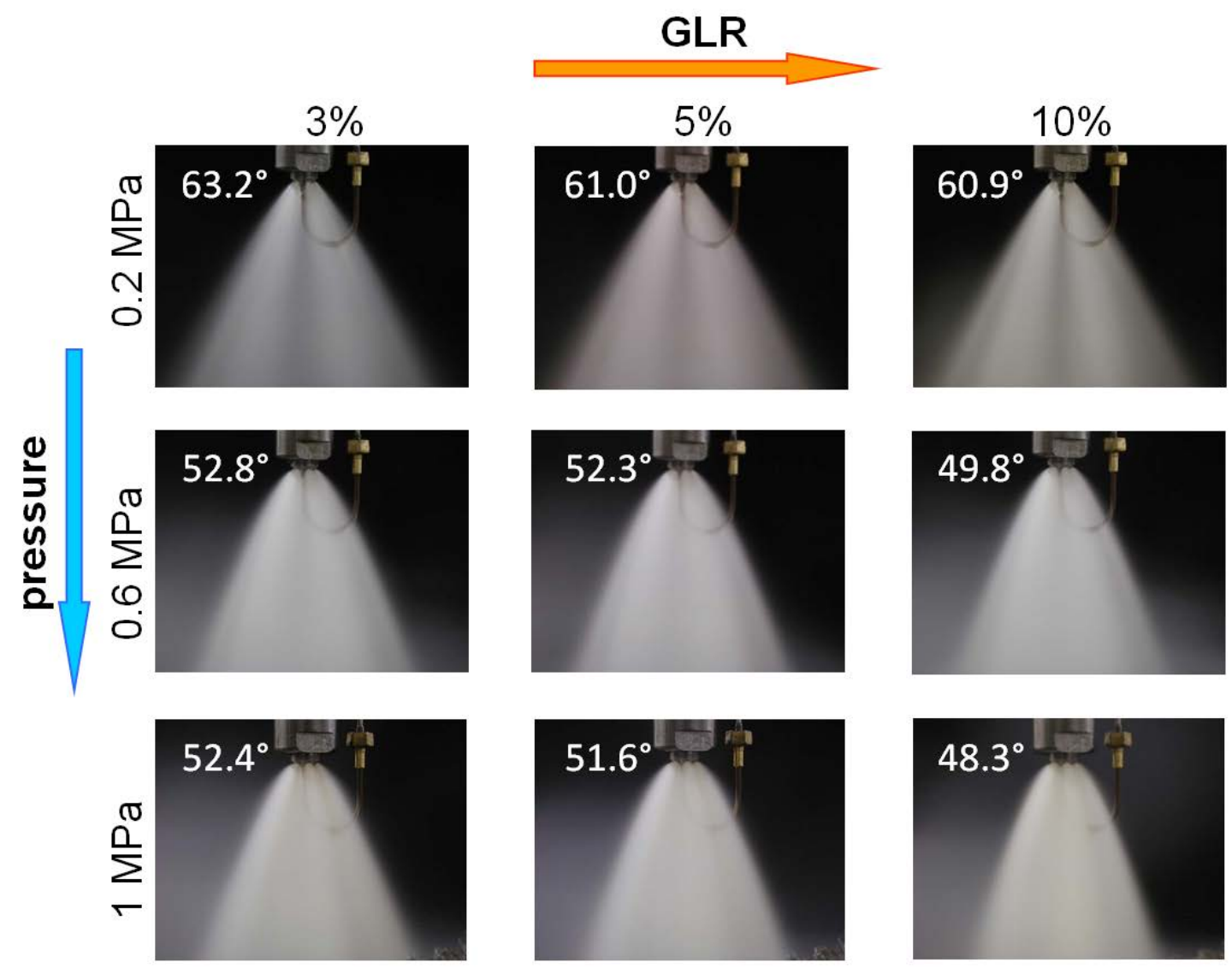

Fig. 2: Spray photography with reported SCAs, atomizer E8.

The six spray jets issuing from the atomizer E8 form a spray cone that visually appears to be relatively consistent and homogeneous. At low pressure and low GLR, the spray streams follow the direction of exit orifice axes, and with an increase in the fluid pressure and/or GLR, the streams tend to incline to the main atomizer axis (an effect of "balling up“ or “wrapping”). The visual SCA is $63.2^{\circ}$ at $p_{g}=0.2 \mathrm{MPa}$ and GLR $=3 \%$ (see Fig. 2 ). It

211 reduces moderately with GLR increase and more significantly with the pressure, i.e. $\mathrm{SCA}=48.3^{\circ}$ at $p_{g}=1 \mathrm{MPa}$ and GLR $=10 \%$. This value is even smaller than the angle formed amongst the axes of the individual orifices, $\alpha$, 
of $60^{\circ}$. These results together with the "wrapped" shape of the spray envelope at high pressures suggest for

214 Coanda effect causing the convergence of individual jets. Also the tendency of the jets to follow the direction of

215 the axially oriented internal flow could have an effect. The merging jets could cause enhanced droplet 216 coalescence and droplet size increase. The "balling up“ effect with GLR increase (followed by the liquid flow

217 rate decrease) is in line with burner requirements as narrower sprays burn well when the power requirement (fuel 218 consumption) is low. On the other hand, the effect of the pressure, followed by flow rate increase, is rather 219 inappropriate.
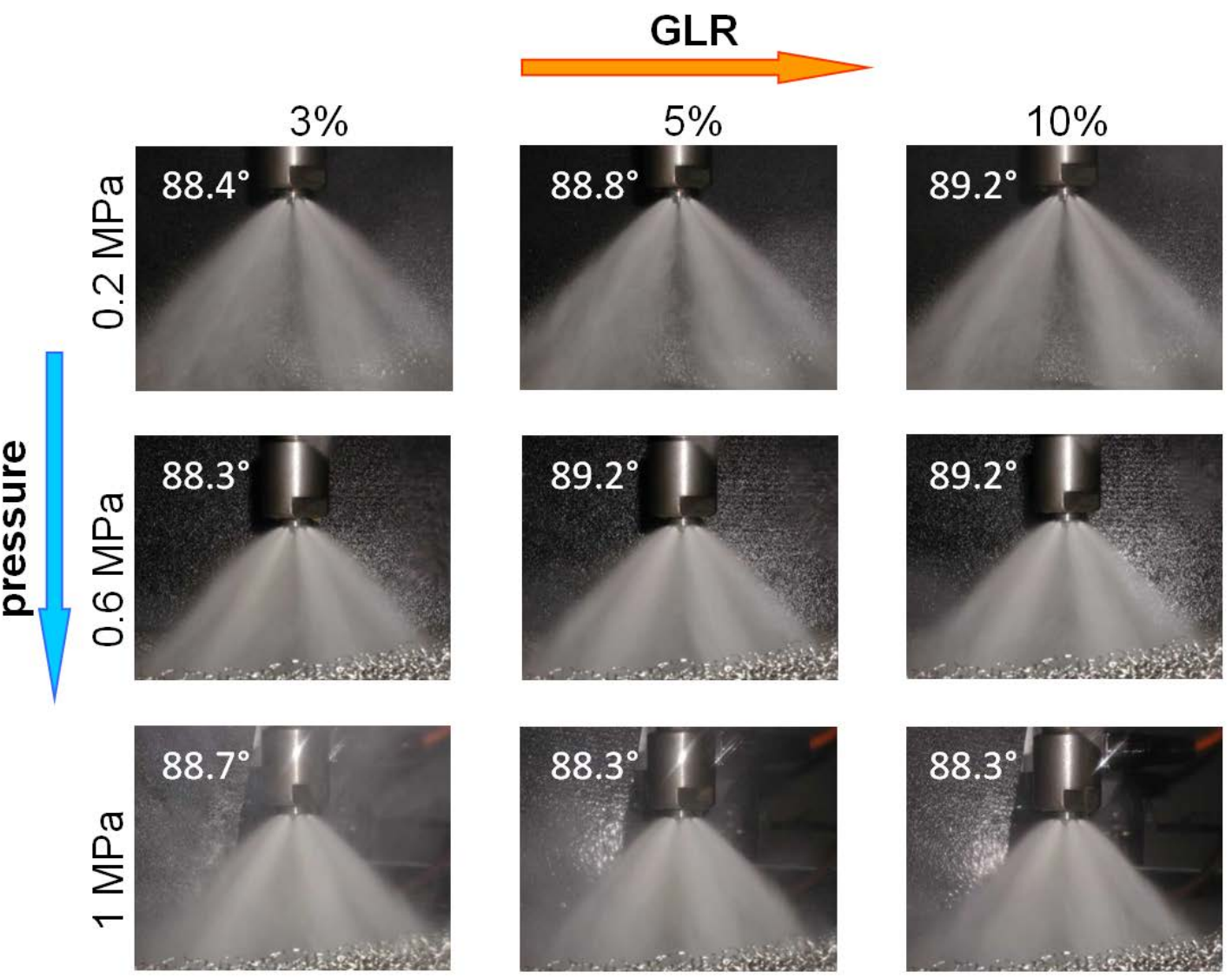

Fig. 3: Spray photography with reported SCAs, atomizer E9.

The spray jets generated by the atomizer E9 form a wider cone that is less homogeneous than in the previous 223 case as the jets are too distant to merge. The atomizer E9 shows almost no effect of the operating conditions on 224 SCA, which spans between 88.3 and $89.2^{\circ}$ within the studied range of operating conditions (see Fig. 3). 
The SCAs formed by atomizers E10 and E12 (whose $\alpha$ agrees with that of E8) show the same character and similar values as the SCA provided by E8, with only a subtle effect of the atomizer internal arrangement. Table 1 reports the turn-down ratio about 1:6 and 1:8 for atomizers E8, E9 and E10, E12 respectively. So, all the atomizers meet the designed flow range requirements.

\subsection{Droplet characteristics}

Measurements of diameter and velocity of individual droplets using the PDA with traversing in multiple planes was made to gain a better insight into the spatial spray structure. A collector and a deflector of spray were installed here to enable the measurements of the spray issuing from one single exit orifice. For this purpose, the atomizers were installed with the axis of this orifice positioned vertically downward. The coordinate system is shown in Fig. 4, on the left. Its origin is located at the exit of the measured orifice. The measurements were made in several planes with grid-point separation of $5 \times 5 \mathrm{~mm}$. The configuration of individual planes was as follows: $\mathrm{XY}$ for $\mathrm{Z}=100,150,200 \mathrm{~mm}, \mathrm{XZ}$ for $\mathrm{Y}=0 \mathrm{~mm}$ and $\mathrm{YZ}$ for $\mathrm{X}=0 \mathrm{~mm}$. The number of measured droplets in each point was limited to 20,000 or by the measurement duration of $30 \mathrm{~s}$, depending on which event occurred first. The points with fewer than 200 samples were excluded from the following analysis. The axial span of the measurement space was limited from the top side to $75 \mathrm{~mm}$ due to the near-nozzle spray that was too dense for optical measurements.

Characteristic spatial distributions of Sauter mean diameter, $D_{32}$, and axial component of the mean velocity,

$243 v_{m}$, in the spray from the individual exit orifice are documented in Fig. 4, in the middle and on the right, 244 respectively. The single-jet spray is relatively symmetrical, according to the centreline of the measured nozzle. 245 The lowest $D_{32}$, about $30 \mu \mathrm{m}$, appears near the centreline. $D_{32}$ slightly increases downstream the spray. It could 246 result from droplet interactions and coalescence as the effervescent sprays are highly turbulent [24]. The highest 247 velocities are found in the nozzle centreline, with the maximum value of $v_{m}=40 \mathrm{~m} \cdot \mathrm{s}^{-1}$ at the axial distance from 248 the orifice $\mathrm{Z}=75 \mathrm{~mm}$ (Fig. 4, on the right). The velocity decays with axial distance as the jet widens and also 249 gradually decreases with radial distance due to the momentum exchange with still surrounding environment. The 250 observed spray structure and character of spatial variation of droplet size and velocity (also resolved below in 251 Fig. 6) are very similar to those of single-hole atomizers studied previously [20]. This similarity of the individual 252 jets from multi-hole atomizer with the single-hole spray was already pointed out by Sovani et al. [10]. They studied a six-hole effervescent diesel injector and stated that single-hole and multi-hole sprays are quite similar, 

characteristics.
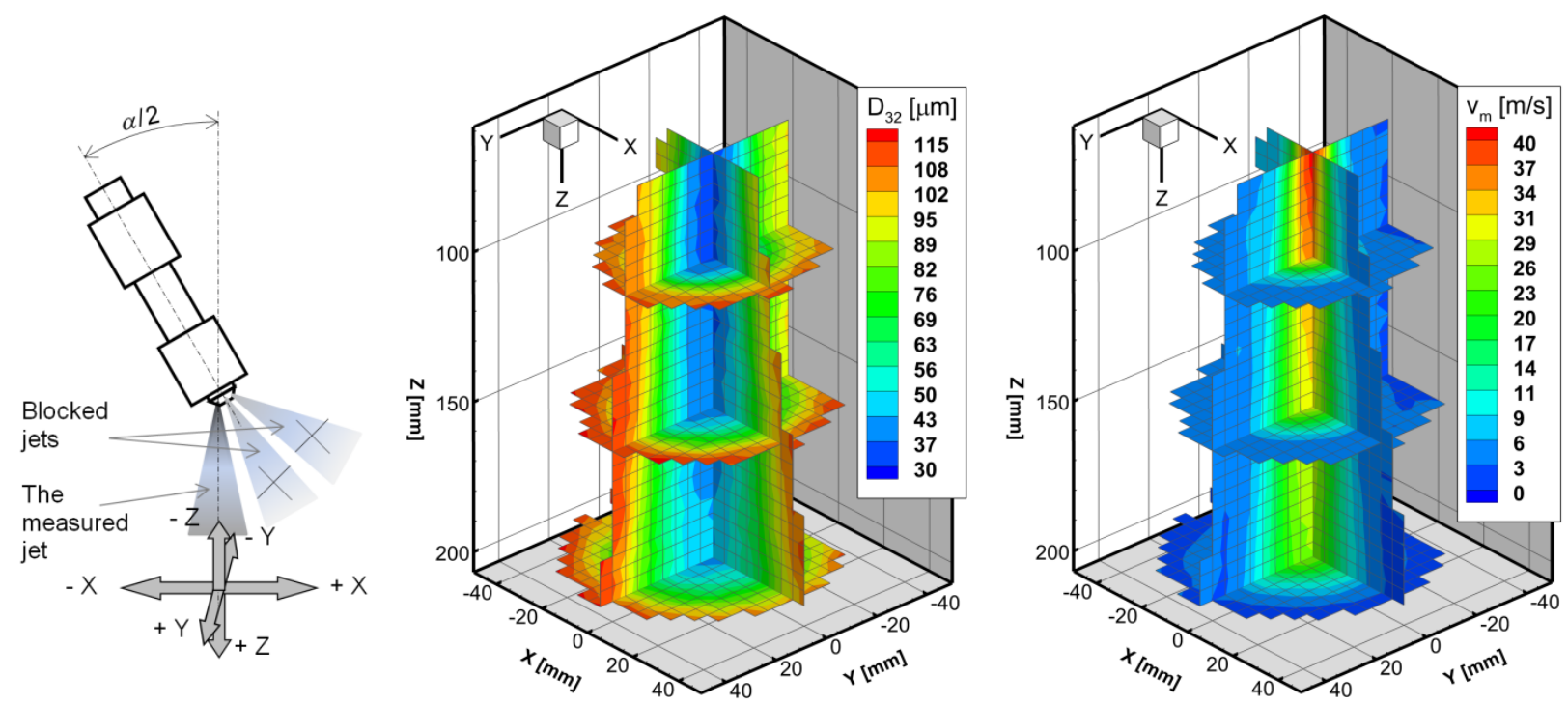

Fig. 4: A schematic view of the inclined atomizer for single-orifice measurement and the Cartesian measurement coordinates (left), $D_{32}$ (middle) and $v_{m}$ (right) in the spray from a single orifice of the multi-hole atomizer E10: $p_{g}=0.6 \mathrm{MPa}, \mathrm{GLR}=0.05$.

The input pressure energy of the gas and liquid is converted into kinetic energy of the discharged two-phase mixture. The gas, inside a rather heterogeneous mixture, is discharged at high velocity compared to the liquid. The liquid fragments accelerate, deform and break up due to drag forces. Small liquid volumes reach greater velocity than large filaments oriented mostly parallel to the flow. The expanding gas decelerates with the distance from the exit orifice. The formed droplets keep the momentum of the parent liquid fragments, so at large distances from the orifice, large droplets are faster than the surrounding air while the velocity of the smallest droplets corresponds to the air velocity [24]. The size-dependent momentum exchange between the two fluids causes a specific and spatially variable correlation between the size and axial velocity of droplets (Fig. 5), where a positive or negative size-velocity correlation appears, depending on radial and axial distances from the nozzle exit. The size-velocity correlation in the axial distance of $152 \mathrm{~mm}$ is distinguishable but weak, regardless of the radial position. These and our further results [26], showing that the size-velocity correlation is 

processes.
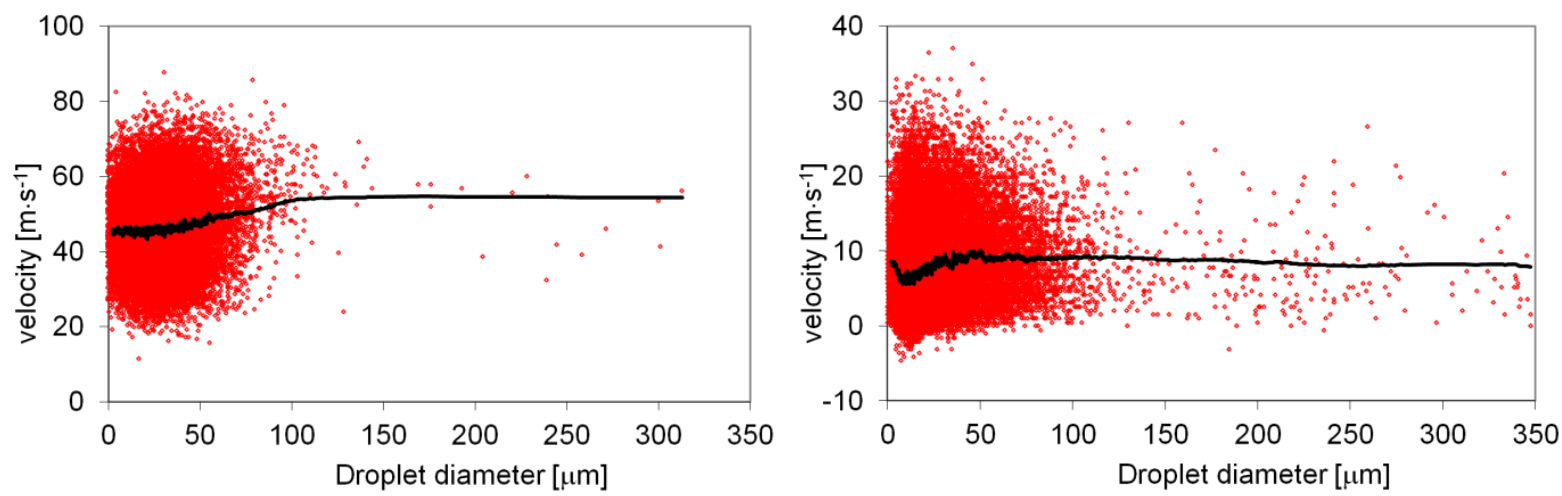

Fig. 5: Diameter-axial velocity correlation, the atomizer E10: $p_{g}=0.6 \mathrm{MPa}$, GLR $=0.05$; left: position $(0,0,152)$, right: position (30, 0, 152). The solid line represents a flowing average per 256 droplets.

The spray at the nozzle axis contains mainly droplets sized bellow $100 \mu \mathrm{m}$, which results in $D_{32}$ of $38.3 \mu \mathrm{m}$. The spray in the radial position of $30 \mathrm{~mm}$ from the nozzle axis features a wider size spectrum; some droplets are even above $350 \mu \mathrm{m}$, which is the maximum value measured by PDA in the present setup. In this position, $D_{32}=74.4 \mu \mathrm{m}$. Such size distributions correspond to findings in [25].

The effect of GLR and fluid inlet pressure on the droplet size and velocity is shown in Fig. 6. The smallest droplets appear at the spray centre where $D_{32}$ ranges between 30 and $40 \mu \mathrm{m}$ and larger droplets occur at the spray edges. The radial size profiles flatten with the increasing axial distance. It could result from the lower energy of the expanding gas on the spray periphery, which causes worse atomization. A higher air pressure and/or higher GLR lead to much flatter profiles. The profiles, varying in such a way, correspond to our previous results for single-hole atomizers [20]. Similar results were presented in [27], but in [24] and [28] a negligible dependence of $D_{32}$ on radial distance from the nozzle axis was found and in [27] even inverse profiles were presented. A possible explanation for such discrepancies could stem from a different internal configuration of these atomizers. An increased air pressure and GLR cause a higher discharge velocity that results in elevated velocity profiles (Fig. 6, on the right) and a reduced droplet size (Fig. 6, on the left) downstream. 

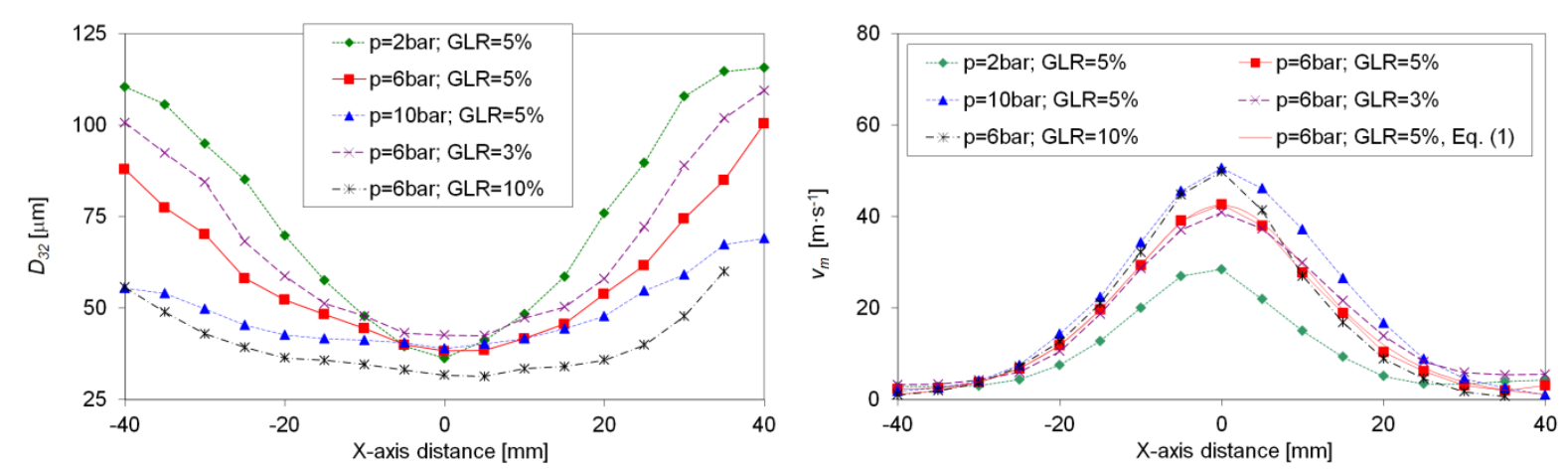

Fig. 6: The dependence of $D_{32}$ (left) and mean axial velocity (right) on $p_{g}$ and GLR for atomizer E10, position $\mathrm{Y}=0 \mathrm{~mm}$, $\mathrm{Z}=152 \mathrm{~mm}$. An approximation of the measured velocity data for $p_{g}=0.6 \mathrm{MPa}$ and GLR $=5 \%$ according to Eq. (1) is included. profile [24]:

$$
v_{m}(x)=v_{m \max } \operatorname{sech}^{2}(\varsigma \cdot x)
$$

agrees well with our results for of $\varsigma=4.1 \cdot 10^{-4}$ at SCHA $<11^{\circ}$ (it corresponds to radial distance of $30 \mathrm{~mm}$ at the axial position of $152 \mathrm{~mm}$ from the exit orifice) as documented in Fig. 6 for $p_{g}=0.6 \mathrm{MPa}$ and GLR $=5 \%$.

The measured particle velocity distribution (Fig. 7) is well approximated by the log-normal statistical distribution. This distribution is almost symmetrical close to the nozzle axis while at larger radial distances where lower droplet velocities occur - it is highly asymmetrical. The particle size distribution in the nozzle axis can be described by the Rosin-Rammler distribution with $\mathrm{R}-\mathrm{R}$ exponent $\alpha_{R}=2.06$. The $\mathrm{R}-\mathrm{R}$ mean droplet diameter $D_{R}=25 \mu \mathrm{m}$ agrees with [7]. Moreover, the log-normal distribution with standard geometric deviation $s_{g}=0.58 \mu \mathrm{m}^{-1}$ and geometric mean drop diameter $D_{n g}=21.5 \mu \mathrm{m}$ gives a good correlation. The Rosin-Rammler and log-normal distributions are defined as follows:

304

$$
f(D)=\frac{1}{\sqrt{2 \pi} D \cdot s_{g}} \exp -\left[\frac{1}{2 s_{g}^{2}}\left(\ln D-\ln \bar{D}_{n g}\right)^{2}\right]
$$



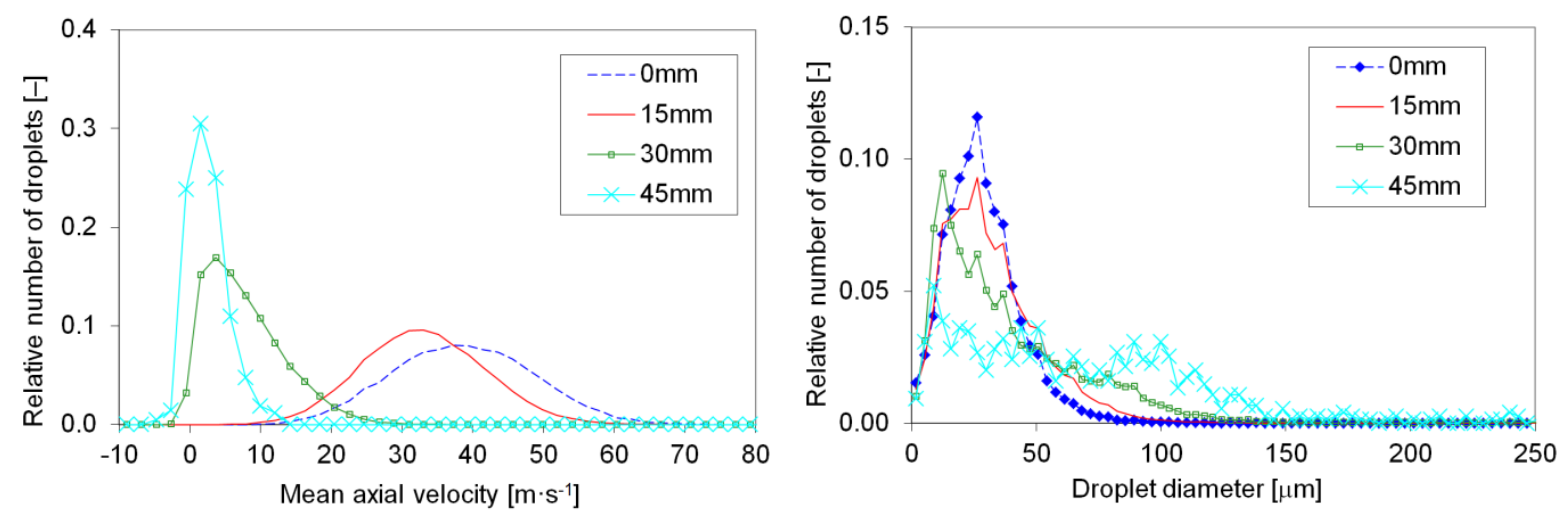

Fig. 7: Particle velocity distribution (left), particle size distribution (right), atomizer E10: $p_{g}=0.6 \mathrm{MPa}$, GLR $=0.05$, position $\mathrm{Y}=0 \mathrm{~mm}, \mathrm{Z}=152 \mathrm{~mm}$, various $\mathrm{X}$-axis positions.

At larger radial distances, large droplets occur together with the small ones, and the distribution changes into bimodal. The second peak corresponds to the drop size of $100 \mu \mathrm{m}$. Such a bimodality or multimodality in drop size distributions were already observed in other twin-fluid sprays [29, 30].

Fig. 8 compares $D_{32}$ in the position $(0,0,152)$ for atomizers E8, E9, E10, and E12. The curves are shifted by $-10 \mu \mathrm{m}$ and $-20 \mu \mathrm{m}$ for $p_{g}$ of $0.6 \mathrm{MPa}$ and 1.0 MPa, respectively to avoid a line-crossing and to improve the visibility. $D_{32}$ reduces with increasing GLR and $p_{g}$ for all the atomizers and all the pressures. However, there are differences in the line slopes amongst the atomizers. E8 (and E9) provide a lower $D_{32}$ at 0.2 and 1.0 MPa than E10 (and E12), but higher $D_{32}$ at $0.6 \mathrm{MPa}$. The differences amongst the atomizers are smaller than $\pm 3 \mu \mathrm{m}$ in the entire measurement range. It means that differences in the total cross-section area of aerator holes and different two-phase flow conditions do not affect $D_{32}$ significantly. The atomizer E8 provides almost the same $D_{32}$ values as E9; we, therefore, can conclude that the angle of the axis of nozzle exit orifice has no effect on the spray quality. A comparison between E10 and E12 indicates no significant influence of the tangential air entry into the aerator.

\subsection{Two-phase flow parameters and conditions}

A mixing process and formation of two-phase flow inside the effervescent atomizers are important steps to 


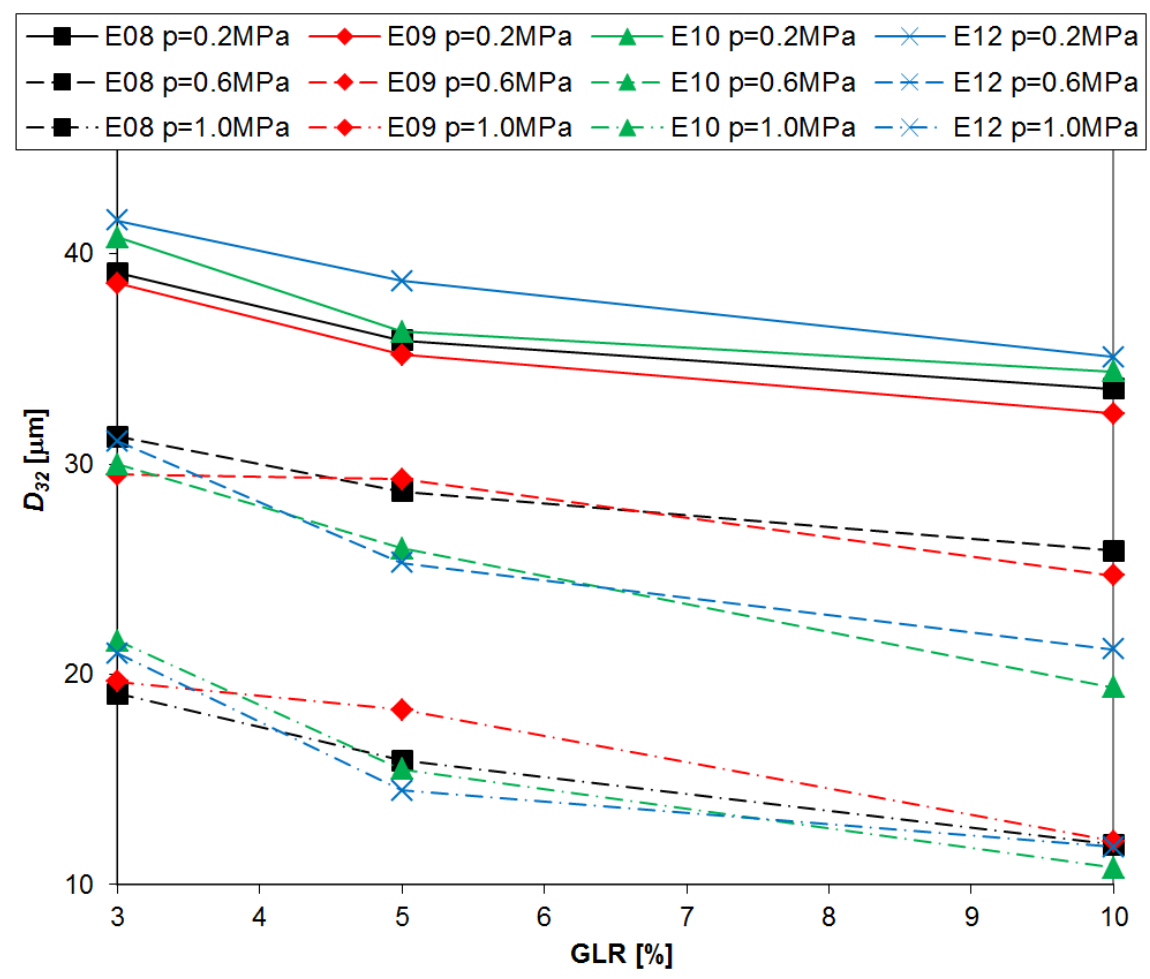

Fig. 8: Influence of $p_{g}$ and GLR on $D_{32}$, position $\mathrm{X}=\mathrm{Y}=0 \mathrm{~mm}, \mathrm{Z}=152 \mathrm{~mm}$.

In this paper, we present the internal two-phase flow using the Baker's map for horizontal two-phase flow, published in [35] and available in [36]. The atomizers E8 and E9 have the same operating conditions and also the differences between E10 and E12 are negligible so that only the two-phase flow regimes for E8 and E10 are discussed here. These atomizers were designed to operate close to the bubbly flow regime. The results in Baker's map (see Fig. 9) follow from the values documented in Table 1; the Baker's map coordinates are as follows: 


$$
\psi=\frac{\sigma_{w}}{\sigma_{l}}\left[\frac{\mu_{l}}{\mu_{w}} \cdot\left(\frac{\rho_{w}}{\rho_{l}}\right)^{2}\right]^{1 / 3} .
$$

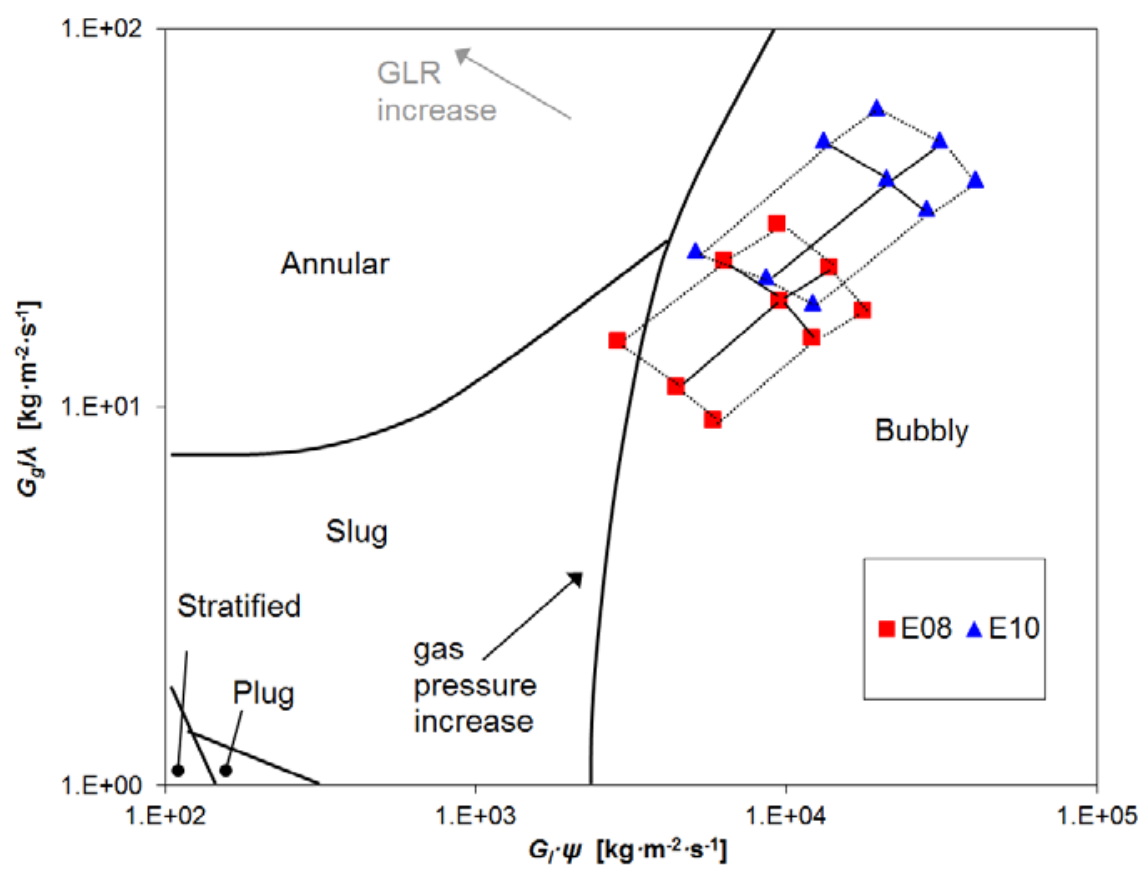

Fig. 9: Fields of operating regimes of atomizers E8 and E10 for combinations of air pressure 0.2, 0.6, 1.0 MPa and GLR 3, 5 and 10\%.

347 Physical properties of water and air as reference fluids are as follows: $\sigma_{w}=0.072 \mathrm{~kg} / \mathrm{s}^{2}, \rho_{w}=1000 \mathrm{~kg} / \mathrm{m}^{3}$, $348 \mu_{w}=0.001 \mathrm{~kg} /(\mathrm{m} \cdot \mathrm{s}), \rho_{a}=1.23 \mathrm{~kg} / \mathrm{m}^{3}$ (standard density). Both the pressure and GLR influence the flow pattern as 349 indicated in Fig. 9 by the arrows. This influence results in different coordinates of the nine operation points of each atomizer in the Baker's map. According to the simple tube model [35], the only one geometrical parameter

351 affecting the flow regime is the cross-sectional area of the mixing chamber. A larger cross-sectional area of E8 352 (E9) shifts the two-phase flow regime closer to the slug flow than it is observed for E10 (E12-E14).

353 We designed a simplified, transparent atomizer to observe the internal two-phase flow with a high-speed 354 video camera; the results for vertically and horizontally positioned atomizer were presented in [31, 37]. Arbitrary 
images of the flow structure of the vertically and horizontally placed atomizer can be seen in Fig. 10. The main conclusion in [37] was that the observed two-phase flow patterns were not always in good agreement with the patterns predicted by maps published for the fully developed two-phase flow. The forces that affect the flow regime are namely as follows: gravitational, inertial, viscous and surface tension. The elevation of mixing chamber does not have a large impact on the flow pattern, but in the case of the horizontal gas-liquid co-flow, a vertical liquid separation can appear under some operating conditions. The separation should be considered when multi-hole atomizers are mounted in a burner horizontally, where it can induce a non-homogenous spray from individual exit orifices. These conclusions were supported by a flame observation in the combustion chamber during our tests with atomizer E9; a heterogeneous flame, namely at low $p_{g}$, indicated a non-uniform GLR distribution caused by the vertical separation of the fluids. The observations in [31] also indicated that a fluctuating mixture at low GLR could result in an unsteady spray.

366

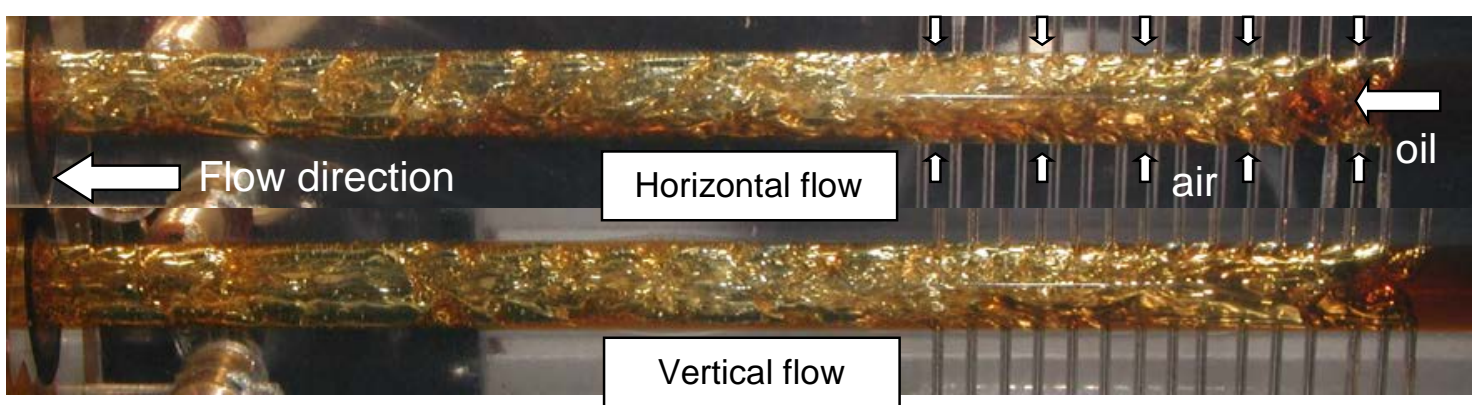

Fig. 10: Visualization of two-phase flow in the vertically and horizontally positioned mixing channel of a transparent effervescent atomizer by a digital camera, with air gauge pressure of $0.1 \mathrm{MPa}$, GLR $=6.5 \%$.

\subsection{Spray homogeneity}

Based on these findings, a distribution of fuel volumetric flow rate into individual exit orifices was measured. The atomizer was run in a horizontal position with a special collector that enabled measuring of fuel volumetric flow rate, $Q_{l}$, through the individual exit orifices without a significant influence on the atomizer operation. The fuel flow rates through the uppermost and the lowermost orifices were measured. We define the non-uniformity of fuel distribution as follows:

$$
k_{l}=\frac{2\left(Q_{l b}-Q_{l t}\right)}{Q_{l b}+Q_{l t}},
$$


377 where the subscript $b$ belongs to the lower orifice and the subscript $t$ to the upper one. The results for atomizers 378 E9, E10, and E12 are documented in Fig. 11. The non-uniformity is much higher for E9 than for E10 and E12. 379 We deduce that a smaller area of the air holes, which lead to a higher air injection velocity, improves the mixing of the gas with liquid and prevents the gravitational gas-liquid separation. The differences between the atomizers E10 and E12 are not significant, so the tangential orientation of the air input to the mixing chamber (E10) is not sufficient to affect the non-uniformity. The operation at low pressure, where lower fluid velocities inside the mixing chamber are achieved, always causes an increase in the $k_{l}$. Moreover, at lower pressure, the two-phase flow regime stands closer to a slug and stratified regimes in Baker’s map (Fig. 9).

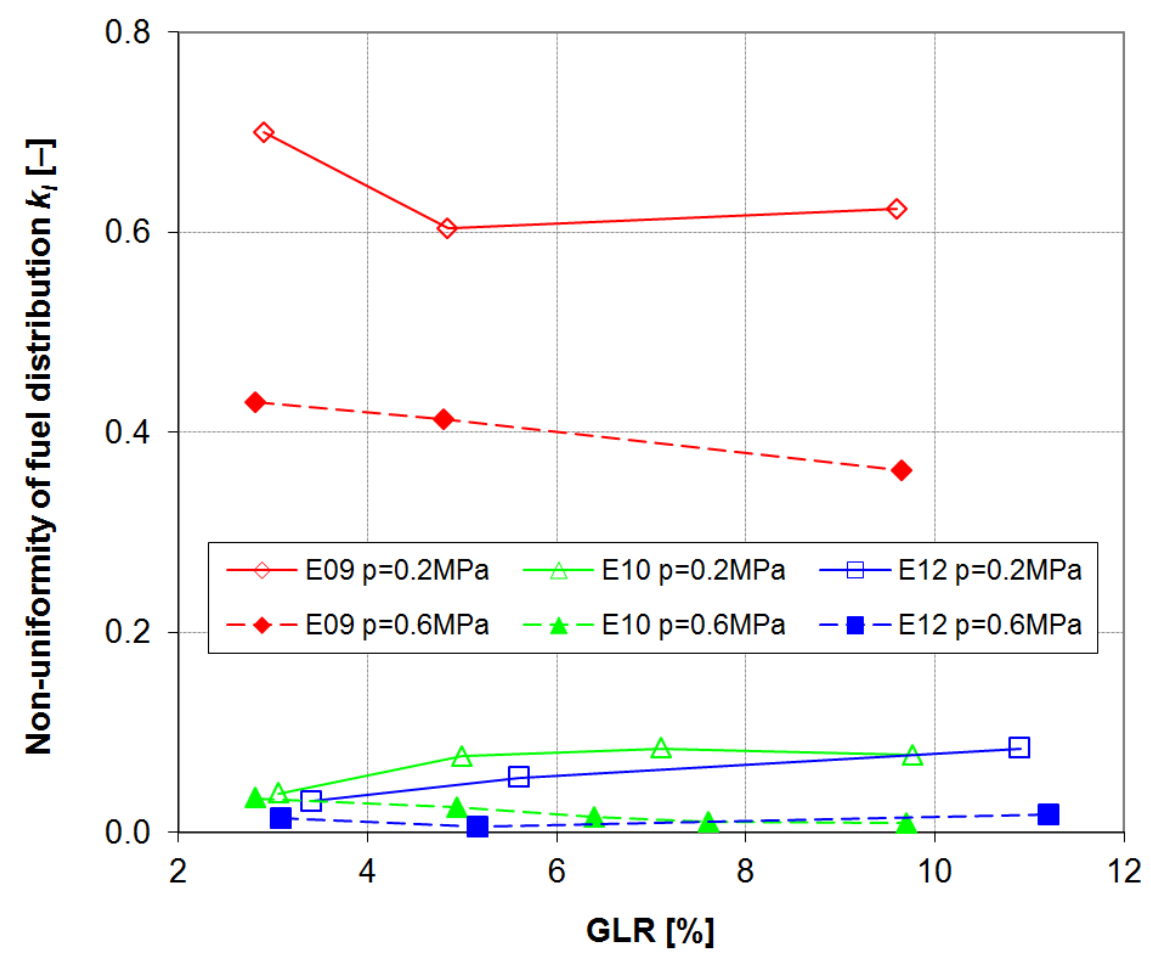

Fig. 11: Non-uniformity of fuel distribution at exit orifices of the multi-hole effervescent atomizers.

We applied a swirling insert inside the mixing chamber to further suppress the $k_{l}$. The helical swirler, located just before the first row of aeration holes, (E14) was intended to rotate the liquid prior to the mixing with the air. We noticed no significant improvement in $k_{l}$ compared to E10 (the E14 results are not shown in Fig. 9 to avoid line overlying). The atomizer E13 with swirler placed close to the exit orifice performed with $k_{l}=0-0.03$, so the mixture homogenization shortly before the atomizer exit helps to significantly and sufficiently reduce the fuel non-uniformity. 
The results presented in Fig. 11, when combined with the relation between the liquid and gas flow rates at given pressure in Table 1, can be used to estimate the actual GLR within the individual orifices. The GLR nonuniformity, $k_{G L R}$, defined according to Eq. (8), where GLR replaces $Q_{l}$, reaches similar values as the nonuniformity in fuel distribution. For example, the atomizer E9 works with $k_{G L R}=1.1$ at $p_{g}=0.2 \mathrm{MPa}$ and GLR $=3 \%$. The observed liquid non-uniformity agrees with [19] where different characteristics of the sprays produced by the individual holes were found out. The difference in GLR into the top and bottom discharge orifices a) has a direct consequence for combustion applications: the top - lean mixture and the bottom - rich mixture, and b) causes corresponding variations in droplet sizes and velocities according to the local GLR values. In combustion applications such as in gas turbines, non-uniform spray patterns result in poor fuel-air mixing, which lowers a combustion efficiency and increases emitted pollutants [6]. As a result of the gravitational gas-liquid separation, it would not be possible to optimize a burner with such an atomizer for low exhaust gas emissions as the bottom part would give a long and smoking flame while the top part would produce a short, fast burning and hot flame.

\subsection{Spray unsteadiness}

The unsteady spray was observed under some operating conditions of the single-hole effervescent atomizer [13, 31]. We developed a method for unsteadiness estimation based on measurements of pressure inside the mixing chamber. A small quartz pressure sensor Kistler 601A for measuring dynamic and quasistatic pressures sensed the pressure fluctuations inside the mixing chamber using a small pipe connected to the chamber at the nozzle tip (the tube with the sensor can be seen in Fig. 2). A RMS value of band pass pressure signal, $p_{R M S}$, serves as an unsteadiness measure; a detailed description of the method is given in [37]. The results for atomizers

414 E8-E12 are presented in Table 1. Values of $p_{R M S}$ higher than $2 \mathrm{kPa}$ suggest for an unsteady spray. All the atomizers tend to be unsteady at low pressure when operating close to the slug flow regime, as it is seen in

416 Fig. 9. Such behaviour of the internal flow, when stable operation at annular flow regime changed into unstable at slug regime, was described by Stähle et al. [38]. No systematic differences amongst the unsteadiness of nozzles E8 to E12 appear based on the data in Table 1. 
We designed and tested several multi-hole effervescent atomizers. The PDA results show that the 422 morphology of spray from the individual orifices is very similar to that of our single-hole nozzles. $D_{32}$ profiles of 423 these atomizers are inversely bell-shaped with the minimum placed to the nozzle axis, in agreement with some researchers. The size-velocity correlation in the individual spray positions is insignificant. A particle size distribution in the nozzle axis can be approximated with the Rosin-Rammler distribution. At a larger radial distance, also large droplets occur and the distribution changes from uni- to bi-modal. GLR and inlet pressure effects also correspond to our findings published earlier and to the results related to the single-hole nozzles of other authors. The internal geometry (inserts, mixing chamber size, and aeration arrangement) affects the internal two-phase flow, but the effect on the droplet size is not significant.

A photographical spray observation was used to describe the spray macrostructure and to estimate the SCAs of the multi-hole effervescent nozzles. The atomizers with a narrow angle amongst the exit orifices showed the SCA reduction in dependence on the pressure and GLR increase while the atomizer with a wide exit orifice angle performed with constant SCA.

A horizontal operation of multi-hole effervescent atomizers leads to the gravitational gas-liquid separation with a difference between the lowermost and uppermost orifices of 0-70\% depending on the nozzle design and flow regime. The reduction of aeration area, close location of the aeration holes to the atomizer exit and mixture homogenization can suppress the non-uniformity of liquid distribution.

A tendency to spray unsteadiness at lower pressure and GLR, which are probably related to a shift from the bubbly flow to the slug flow, was evidenced and can be prevented by a choice of the appropriate operating conditions and a careful atomizer design.

Our findings show that the internal geometry of multi-hole effervescent atomizer significantly affects the spray characteristics with consequences in the combustion applications. The results are important for the atomizer design and optimization of the burner to improve combustion efficiency and reduce exhaust gas emissions.

\section{Nomenclature}




\begin{tabular}{|c|c|c|c|}
\hline 451 & $D_{n g}$ & geometric mean droplet diameter used in Eq. (2) & $(\mu \mathrm{m})$ \\
\hline 452 & $D_{R}$ & mean droplet diameter used in Eq. (3) & $(\mu \mathrm{m})$ \\
\hline 453 & $G$ & mass flux & $\left(\mathrm{kg} \cdot \mathrm{m}^{-2} \cdot \mathrm{s}^{-1}\right)$ \\
\hline 454 & GLR & Gas-to-Liquid mass flow-rate Ratio & $(\%,-)$ \\
\hline 455 & $k_{l}$ & non-uniformity of fuel distribution as defined in Eq. (8) & $(\%,-)$ \\
\hline 456 & $l$ & an atomizer length dimension, specified by a subscript & $(\mathrm{mm})$ \\
\hline 457 & $p$ & gauge pressure & $(\mathrm{MPa})$ \\
\hline 458 & $p_{R M S}$ & spray unsteadiness & $(\mathrm{kPa})$ \\
\hline 459 & $Q$ & volumetric flow rate & $\left(\mathrm{ml} \cdot \mathrm{s}^{-1}\right)$ \\
\hline 460 & $r$ & a dimension ratio, specified by a subscript & $(-)$ \\
\hline 461 & $s_{g}$ & standard geometric deviation used in Eq. (2) & $\left(\mu \mathrm{m}^{-1}\right)$ \\
\hline 462 & SCA & Spray Cone Angle & $(\mathrm{deg})$ \\
\hline 463 & SCHA & Spray Cone Half-Angle & $(\mathrm{deg})$ \\
\hline 464 & $v$ & velocity & $\left(\mathrm{m} \cdot \mathrm{s}^{-1}\right)$ \\
\hline 465 & $\mathrm{X}, \mathrm{Y}, \mathrm{Z}$ & Cartesian coordinates ( $\mathrm{Z}$ = axial distance) & $(\mathrm{mm})$ \\
\hline 466 & $x$ & relative radial distance, $x=X / Z$ & $(-)$ \\
\hline \multicolumn{4}{|l|}{467} \\
\hline 468 & \multicolumn{3}{|c|}{ Greek characters } \\
\hline 469 & $\alpha$ & full angle amongst the axes of the individual orifices & (deg) \\
\hline 470 & $\alpha_{R}$ & exponent in the Rosin-Rammler distribution & $(-)$ \\
\hline 471 & $\Delta l$ & span length & $(\mathrm{mm})$ \\
\hline 472 & $\Delta_{p}$ & difference between the inlet air and fuel pressures, $\Delta_{p}=p_{g}-p_{l}$ & $(\mathrm{kPa})$ \\
\hline 473 & $\mu$ & dynamic viscosity & $\left(\mathrm{kg} \cdot \mathrm{m}^{-1} \cdot \mathrm{s}^{-1}\right)$ \\
\hline 474 & $\rho$ & density & $\left(\mathrm{kg} / \mathrm{m}^{3}\right)$ \\
\hline 475 & $\sigma$ & liquid/gas surface tension & $\left(\mathrm{kg} / \mathrm{s}^{2}\right)$ \\
\hline 476 & $\varsigma$ & parameter used in Eq. (1) & $(-)$ \\
\hline \multicolumn{4}{|l|}{477} \\
\hline 478 & \multicolumn{3}{|c|}{ Subscripts } \\
\hline 479 & $a$ & air, aeration & \\
\hline 480 & $b$ & bottom (orifice) & \\
\hline
\end{tabular}




$\begin{array}{lll}481 & c & \text { mixing chamber } \\ 482 & g & \text { atomizing gas (air) } \\ 483 & l & \text { atomized liquid (light heating oil, LHO) } \\ 484 & m & \text { mean value } \\ 485 & \text { max } & \text { maximum value } \\ 486 & o & \text { the final discharge orifice } \\ 487 & t & \text { top (orifice) } \\ 488 & w & \text { water }\end{array}$

489

Abbreviations:

491

LHO Light Heating Oil

492

PDA Phase-Doppler Anemometer

493

RMS Root-Mean-Square

494

Acknowledgement

The authors gratefully acknowledge the financial support from the Ministry of Education, Youth and Sports of the Czech Republic within the framework of project No. CZ.1.05/2.1.00/19.0397, NETME Centre TechUp.

\section{References}

[1] Yaman, S., Pyrolysis of biomass to produce fuels and chemical feedstocks. Energy Conversion and Management, 2004, 45, (5), 651-671.

[2] Altın, R.; Çetinkaya, S.; Yücesu, H.S., The potential of using vegetable oil fuels as fuel for diesel engines. Energy Conversion and Management, 2001, 42, (5), 529-538.

504 [3] Karabektas, M.; Ergen, G.; Hosoz, M., The effects of preheated cottonseed oil methyl ester on the performance and exhaust emissions of a diesel engine. Applied Thermal Engineering, 2008, 28, (17-18), 21362143.

507 [4] Lefebvre, A.H. Atomization and sprays. Hemisphere Pub. Corp.: New York, 1989.

508 [5] Dikshit, S.; Channiwala, S.; Kulshreshtha, D.; Chaudhari, K.; ASME, 2009.

[6] Gupta, A.K., Gas turbine combustion: Prospects and challenges. Energy Conversion and Management, 1997, 38, (10-13), 1311-1318.

511 [7] Whitlow, J.D.; Lefebvre, A.H., Effervescent Atomizer Operation and Spray Characteristics. 512 Atomization and Sprays, 1993, 3, (2), 137-155.

513 [8] Chen, S.K.; Lefebvre, A.H., SPRAY CONE ANGLES OF EFFERVESCENT ATOMIZERS. 514 Atomization and Sprays, 1994, 4, (3), 291-301.

515 [9] Wade, R.A.; Weerts, J.M.; Sojka, P.E.; Gore, J.P.; Eckerle, W.A., Effervescent atomization at injection 516 pressures in the MPa range. Atomization and Sprays, 1999, 9, (6), 651-667. 
[10] Sovani, S.D.; Crofts, J.D.; Sojka, P.E.; Gore, J.P.; Eckerle, W.A., Structure and steady-state spray performance of an effervescent diesel injector. Fuel, 2005, 84, (12-13), 1503-1514.

[11] Sovani, S.D.; Chou, E.; Sojka, P.E.; Gore, J.P.; Eckerle, W.A.; Crofts, J.D., High pressure effervescent atomization: effect of ambient pressure on spray cone angle. Fuel, 2001, 80, (3), 427-435.

[12] Gong, J.S.; Fu, W.B., The experimental study on the flow characteristics for a swirling gas-liquid spray atomizer. Applied Thermal Engineering, 2007, 27, (17-18), 2886-2892.

[13] Jedelsky, J.; Jicha, M., SPATIALLY AND TEMPORALLY RESOLVED DISTRIBUTIONS OF LIQUID IN AN EFFERVESCENT SPRAY. Atomization and Sprays, 2012, 22, (7), 603-626.

[14] Whitlow, J.D.; Lefebvre, A.H.; Rollbuhler, J.R. In Proc. AGARD 1993, 1993, pp 536, 538/531$538 / 511$.

[15] Li, J.; Lefebvre, A.H.; Rollbuhler, J.R. In American Society of Mech. Engineers 1994, 1994; Vol. 94GT-495, pp 1-6.

[16] Dutta, P.; Gore, J.P.; Sivathanu, Y.R.; Sojka, P.E., GLOBAL PROPERTIES OF HIGH LIQUID LOADING TURBULENT CRUDE-OIL PLUS METHANE AIR SPRAY FLAMES. Combustion and Flame, 1994, 97, (3-4), 251-260.

[17] Moore, C.E. DESIGN, DEVELOPMENT, AND ANALYSIS OF A TWIN-FLUID FIRE SUPPRESSION ATOMIZER AND CHARACTERIZATION OF ELECTROSTATICALLY CHARGED DROPLET SPRAYS. B.S. University of Southern Mississippi, Southern Mississippi, 2003.

[18] Barreras, F.; Lozano, A.; Barroso, J.; Lincheta, E., EXPERIMENTAL CHARACTERIZATION OF INDUSTRIAL TWIN-FLUID ATOMIZERS. 2006, 16, (2), 127-146.

[19] Sovani, S.D.; Sojka, P.E.; Lefebvre, A.H., Effervescent atomization. Progress in Energy and Combustion Science, 2001, 27, (4), 483-521.

[20] Jedelsky, J.; Jicha, M.; Slama, J.; Otahal, J., Development of an Effervescent Atomizer for Industrial Burners. Energy \& Fuels, 2009, 23, 6121-6130.

[21] Lorcher, M.; Schmidt, F.; Mewes, D., Effervescent atomization of liquids. Atomization and Sprays, 2005, 15, (2), 145-168.

[22] Lefebvre, A.H.; Chin, J.S., FLOW PATTERNS IN INTERNAL-MIXING, TWIN-FLUID ATOMIZERS. 1993, 3, (4), 463-475.

[23] Jedelsky, J.; Jicha, M.; Slama, J. In Proc. of 9th ICLASS 2003, 2003, p 311.

[24] Panchagnula, M.V.; Sojka, P.E., Spatial droplet velocity and size profiles in effervescent atomizerproduced sprays. Fuel, 1999, 78, (6), 729-741.

[25] Morelli, F.; Ligasacchi, S.; Bizzarri, M. In Proc. ICLASS 2003, 2003.

[26] Jedelsky, J.; Jicha, M., Energy conversion during effervescent atomization. Fuel, 2013, 111, 836-844.

[27] Sankar, S.V.; Robart, D.M.; Bachalo, W.D. In ASME HTD 1995, 1995, pp 317-312, 175-182.

[28] Kufferath, A.; Wende, B.; Leuckel, W., Influence of liquid flow conditions on spray characteristics of internal-mixing twin-fluid atomizers. International Journal of Heat and Fluid Flow, 1999, 20, (5), 513-519.

[29] Broukal, J.; Hájek, J., Validation of an effervescent spray model with secondary atomization and its application to modeling of a large-scale furnace. Applied Thermal Engineering, 2011, 31, (13), 2153-2164.

[30] Juslin, L.; Antikainen, O.; Merkku, P.; Yliruusi, J., Droplet size measurement: I. Effect of three independent variables on droplet size distribution and spray angle from a pneumatic nozzle. International Journal of Pharmaceutics, 1995, 123, (2), 247-256.

[31] Jedelsky, J.; Jicha, M., Unsteadiness in effervescent sprays: A new evaluation method and the influence of operational conditions. Atomization and Sprays, 2008, 18, (1), 49-83.

[32] Liu, M.; Duan, Y.F.; Zhang, T.N., Evaluation of effervescent atomizer internal design on the spray unsteadiness using a phase/Doppler particle analyzer. Experimental Thermal and Fluid Science, 2010, 34, (6), 657-665.

[33] Gadgil, H.P.; Raghunandan, B.N., Some features of spray breakup in effervescent atomizers. Experiments in Fluids, 2011, 50, (2), 329-338.

[34] Liu, M.; Duan, Y.F.; Zhang, T.N.; Xu, Y.Q., Evaluation of unsteadiness in effervescent sprays by analysis of droplet arrival statistics - The influence of fluids properties and atomizer internal design. Experimental Thermal and Fluid Science, 2011, 35, (1), 190-198.

[35] Wallis, G. One Dimensional Two-Phase Flow. Mcgraw-Hill (Tx), August 1969.

[36] Jedelsky, J.; Michalica, K. Modified Baker's map with transformed coordinates for vertical and horizontal fully developed gas-liquid two-phase flow. http://www.energetickeforum.cz/ext/2pf/maps/ (9.7.2015), [37] Jedelsky, J.; Jicha, M. In International Symposium on Two-Phase Flow Modelling and Experimentation: Pisa, Italy, 2004.

[38] Stähle, P.; Gaukel, V.; Schuchmann, H.P., Investigation on the Applicability of the Effervescent Atomizer in Spray Drying of Foods: Influence of Liquid Viscosity on Nozzle Internal Two-Phase Flow and Spray Characteristics. Journal of Food Process Engineering, 2015, n/a-n/a. 